\title{
ARTE, CIÊNCIA E TECNOLOGIA NA ARBORIZAÇÃO URBANA
}

WANTUELFER GONÇALVES

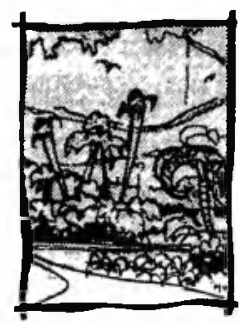

A ARBORIZAÇĀO urbana é uma atividade que mescla arte, ciência e tecnologia na busca de sensações visuais agradáveis contornando problemas advindos da harmonização entre os elementos naturais (árvores) e os elementos construídos.

$O$ vegetal tem um papel definido na paisagem, semelhante a qualquer elemento construído, já que ele desempenha papel de paredes, tetos e pisos na composição dos espaços (MACEDO, 1990).

Para desempenhar esses papéis, o vegetal é usado segundo a sua forma externa, que é função do seu genótipo, sendo a árvore um elemento essencial, cuja forma depende de sua arquitetura. Cada espécie possui um modelo arquitetônico próprio (HALLE et al., 1978) e se presta para alguma composição específica na ARBORIZAÇÃO.

No entanto, para o uso desse modelo específico, o arborizador depara com barreiras físicas que precisam ser contornadas, onde estruturas urbanas subterrâneas e fiações são as mais sérias. Para citar algumas apenas, basta dizer que a interrupção de energia chega a 50\% em algumas cidades (MAGALHÃES et al., 1991) e que a redução no nível de iluminação pode chegar a $71 \%$ (SARTORI NETO, 1988) em função do uso inadequado de árvores na ARBORIZAÇÃO urbana.

\section{AS CONDIÇÕES DA ARBORIZAÇÃO URBANA}

A ARBORIZAÇÃO urbana, além de levar em conta detalhes como textura, cor, beleza, enfrenta outros problemas que exigem do técnico uma atenção redobrada, porquanto existem muitas CONDIÇÕES que devem ser atendidas simultaneamente. Essas CONDIÇÕES são de conhecimento geral e são aqui apenas enumeradas e abordadas superficialmente para situação do assunto.

Os problemas ou CONDIÇŌES mais comuns, enfrentados no dia a dia do técnico são: substituição de árvores, levantamento de calçadas e paredes, depredação, fenologia, combinação arquitetônica, fiação, espaço para ARBORIZAÇÃO. 


\section{SUBSTITUIÇÃO DE ÁRVORES}

Muito comum na atividade de ARBORIZAÇÃO urbana é a necessidade de troca de árvores, quer seja pela senilidade, quer seja pela inconveniência da espécie, quer seja por motivos de enfermidade. $\mathrm{Na}$ época da troca há que se contentar com a coexistência de indivíduos, num mesmo local, de idades diferentes, com modificação radical do visual paisagístico. Se a substituição é total, o impacto pode ser menor que substituições pontuais.

\section{LEVANTAMENTO DE CALÇADAS E PAREDES}

Decorrente da formação radicular da planta, esse problema é comum quando uma árvore de raízes superficiais é plantada em local inapropriado. Logicamente o técnico procurará o uso de uma espécie de raiz pivotante para locais onde haja muros e calçadas tão próximos. No entanto, do ponto de vista paisagístico, por combinação arquitetônica, pode ser que a espécie que melhor se adeque ao ambiente seja uma espécie que tenha um formato de copa aberta (Fig. 1), cujas raízes sejam problema. Nesse caso há que se decidir entre a copa ideal e a raiz imprópria.

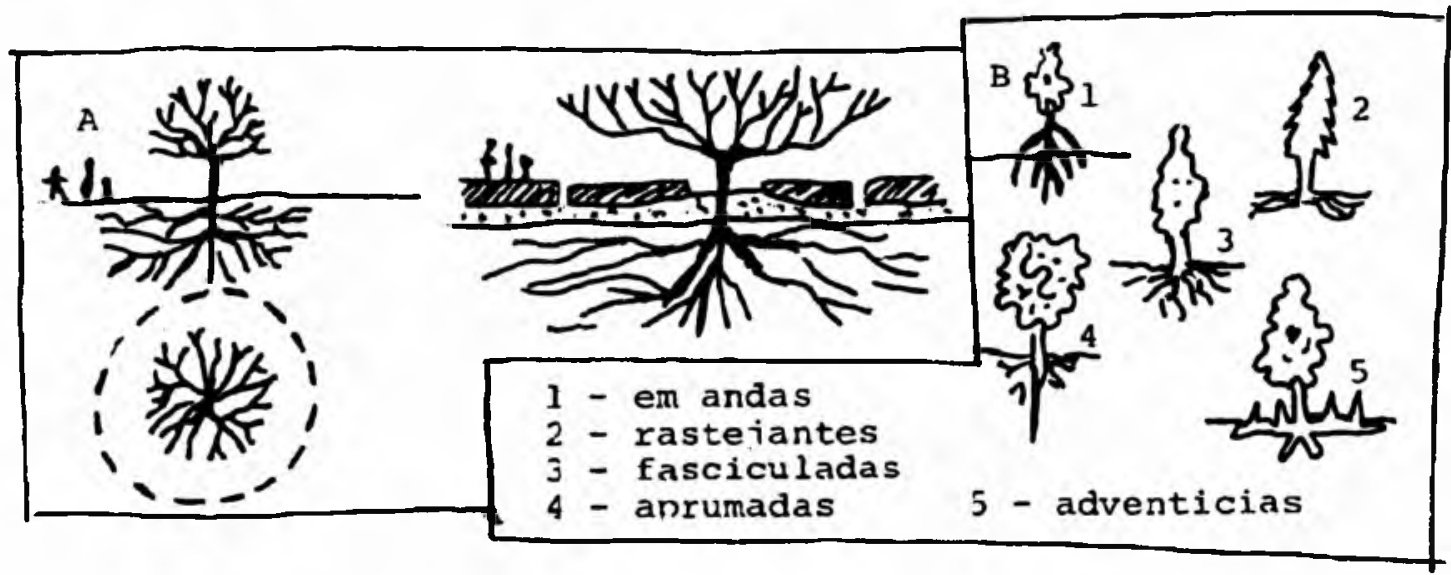

FIGURA 1 - Problemas causados pela raiz

(A) Proporçāo raiz/parte aérea Fonte: Laurie (1975)

(B) Tipos de raízes Fonte: Fischesser (1980)

\section{DEPREDAÇÃO}

$\mathrm{Na}$ fase de implantação da arborização urbana enfrenta-se o problema grave da DEPREDAÇÃO das mudas tanto por animais quanto pelo povo. No que se refere ao povo, embora seja sabido que essa é uma questão de educação a ser re- 
solvida a médio e longo prazos, adota-se como paliativo imediato o uso de grades protetoras e de mudas mais desenvolvidas.

\section{FENOLOGIA}

Esse é um problema comum e de difícil solução. Algumas espécies apresentam uma variabilidade enorme de forma e de cor, conforme a época do ano e isso altera sobremaneira a paisagem. $\mathrm{O}$ ipê (Tabebuia $s p$ ) por exemplo, tem seu período só de flores, só de folhas e só de galhos. Por mais que se tente uma combinação perfeita do vegetal com o entorno, a efemeridade da floração ou da queda de folhas faz a variação. Assim, a consulta de uma tabela de épocas de floração serve por muito pouco tempo como valor paisagístico se, em muitos casos, a convivência com as folhas ou com a falta delas for muito maior.

\section{COMBINAÇÃO ARQUITETÔNICA}

A combinação arquitetônica deve representar a preocupação maior do arborizador, na medida em que é ela que proporcionará a sensação visual agradável ou não pela combinação da arquitetura das árvores com o entorno. A escolha adequada do vegetal em termos de textura, forma, tamanho, cor, complementa as linhas arquitetônicas através de quebras de linha, redução/alargamento de espaços, bem como, através de sequiências, repetições, ritmos e escalas pode transmitir beleza ou fadiga (GREY, DENEKE, 1978).

A indicação/implantação da arborização deve obedecer a um estudo prévio do ambiente, onde deverão ser contemplados: situação do local dentro da cidade, o tipo e o tamanho dos lotes, as construções na divisa ou com afastamento, o tipo de atividade mais comum no local, a existência de redes elétricas e pavimentação, o abastecimento de água, o entorno (IEF, s.d.).

A dificuldade do arborizador está no atendimento da estética e dos fatores físicos locais a um só tempo.

\section{FIAÇÃO/ESPAÇO}

Dos fatores físicos cerceadores da criação estética, a fiação e o espaço a ser ocupado pela arborizaçāo, tanto o aéreo como o subterrâneo, são os mais importantes. Essas condições influenciam na escolha da árvore em termos de porte e arquitetura, determinando formas e critérios pouco recomendáveis de podas se a espécie é mal escolhida (MAGALHĀES, 1991).

Seguir a recomendação de guias propostas por companhias de energia elétrica (MAGALHÃES, 1991; IEF, s.d.) (Fig. 2 e Quadro 1) é conveniente para contornar os fatores físicos mas o atendimento estético não deixa de ser cerceado. 


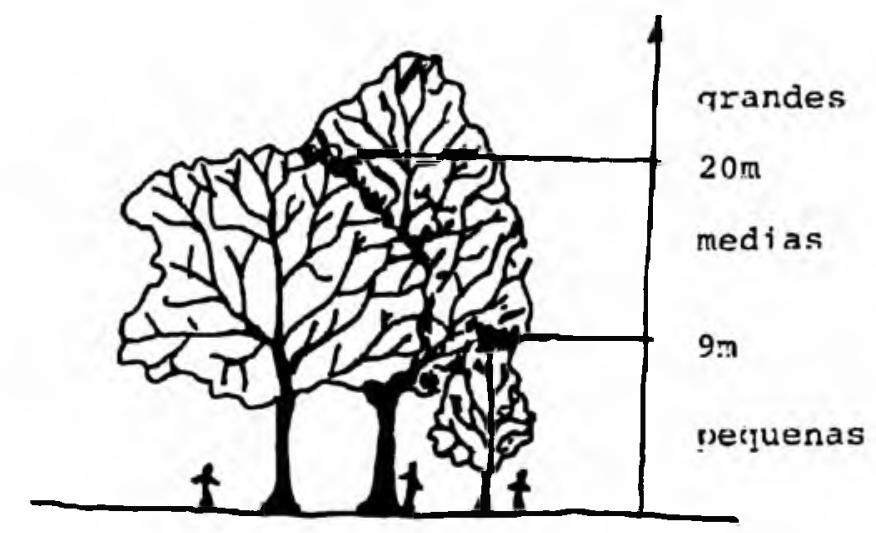

FIGURA 2 - Porte de árvores adultas para arborização

Fonte: Grey e Deneke (1978)

QUADRO 1 Indicações de espécies apropriadas para arborização

\begin{tabular}{|c|c|c|c|c|c|}
\hline \multicolumn{2}{|c|}{ LARGURA } & \multicolumn{2}{|c|}{ SITUAÇĀO CONSTRUÇÃO } & \multicolumn{2}{|c|}{ PLANTIO ESPÉCIE } \\
\hline RUA & PASSEIO & NA DIVISA & COMRECUO & PORTE & LOCAL \\
\hline \multirow{4}{*}{$6,0 \mathrm{~m}$} & \multirow{2}{*}{$2,5 \mathrm{~m}$} & $\operatorname{sim}$ & & & não aborizar \\
\hline & & & $\operatorname{sim}$ & pequeno & dentro propried. \\
\hline & \multirow{2}{*}{$2,5 \mathrm{~m}$} & $\operatorname{sim}$ & & pequeno & oposto fiaçăo \\
\hline & & & $\operatorname{sim}$ & pequeno & $\begin{array}{l}\text { oposto fiaçāo } \\
\text { dentro propried. }\end{array}$ \\
\hline \multirow{4}{*}{$9,0 \mathrm{~m}$} & \multirow[b]{2}{*}{$2,5 \mathrm{~m}$} & $\operatorname{sim}$ & & médio & oposto fiação \\
\hline & & & $\operatorname{sim}$ & médio & $\begin{array}{l}\text { oposto fiaçāo } \\
\text { dentro propried. }\end{array}$ \\
\hline & \multirow{2}{*}{$2,5 \mathrm{~m}$} & $\sin$ & & grande & oposto fiaçāo \\
\hline & & $\operatorname{sim}$ & $\operatorname{sim}$ & pequeno & sob fiaçāo \\
\hline \multirow{4}{*}{$12,0 \mathrm{~m}$} & \multirow[b]{2}{*}{$2,5 \mathrm{~m}$} & $\operatorname{sim}$ & & grande & oposto fiação \\
\hline & & & $\operatorname{sim}$ & pequeno & sob fiaçāo \\
\hline & \multirow{2}{*}{$2,5 \mathrm{~m}$} & $\operatorname{sim}$ & & grande & oposto fiação \\
\hline & & $\operatorname{sim}$ & & pequeno & sob fiação \\
\hline
\end{tabular}

Fonte: IEF (s.d.)

A combinação de espécies florestais ao natural se faz harmonicamente. Quando de um plantio artificial, embora a tarefa não seja fácil, a combinação dessas es- 
pécies se mostra menos difícil que a combinação entre árvores e elementos construídos. $O$ paisagista urbano trabalha com essa dificuldade que é a harmonização do natural com o construído.

A arquitetura do elemento construído é concebida de acordo com o desejo do profissional que deve estar de conformidade com o entorno ou com alguma necessidade estética. A arquitetura da árvore é fixa, cabendo ao profissional a escolha de uma ou de outra, conforme sua concepção de conjunto. Essa arquitetura é função da ramificação, da disposição dos galhos, do tipo de crescimento, conforme um padrão próprio, definido pelo genótipo.

Se a árvore possui um eixo principal perfeitamente definido, com grande crescimento e ramos laterais menores, ascendentes ou horizontais, ela tem uma ramificação racemosa.

Se ela possui um eixo principal curto que à pouca altura divide-se em dois ou mais e estes, por sua vez, tornam a se subdividir, sua ramificação é cimosa (RAMALHO, 1976).

Assim, essa diferenciação da ramificação está em função da longevidade da gema apical, onde a gema apical com vida indefinida gera troncos monopodiais e com vida limitada gera troncos simpodiais (Fig. 3). O simpodismo está, então, em função da mudança de direção no crescimento dos meristemas ou na diferenciação de atividades vegetativas e sexuais (Fig. 4), gerando arquiteturas orto e plagiotrópicas.
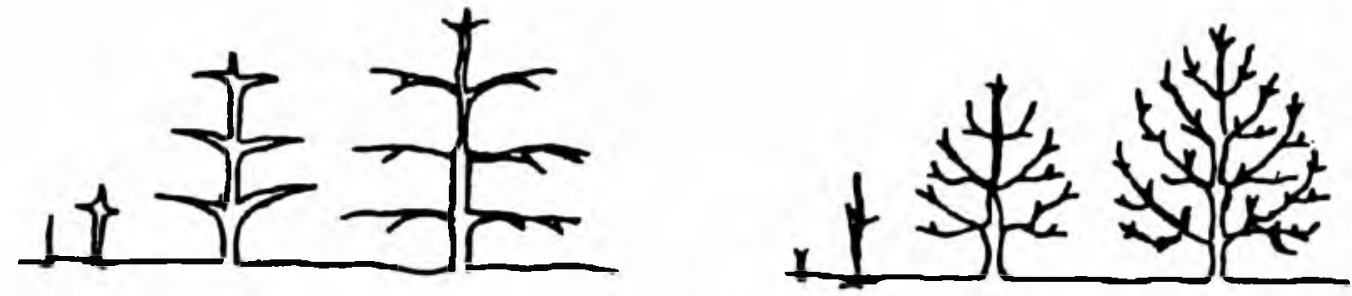

FIGURA 3 - Troncos simpodiais e monopodiais.

Fonte: Seitz (1990).
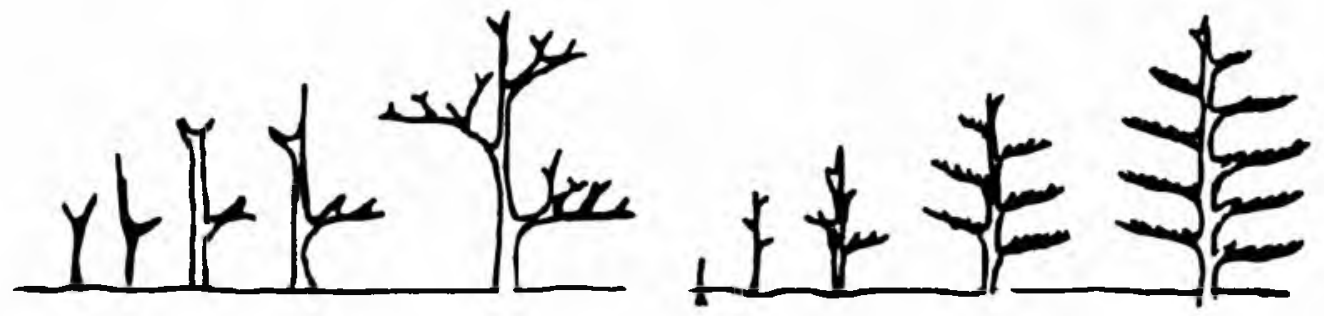

FIGURA 4 - Eixos ortotrópicos e plagiotrópicos.

Fonte: Seitz (1990)

Um terceiro elemento que determina a arquitetura da árvore é a disposição dos galhos no tronco. Quanto ao tipo de inserção ela pode ser verticulada, decussada 
ou alternada (RAMALHO, 1976) e quanto ao ângulo horizontal, agudo ou vertical (GREY, DENEKE, 1978) (Fig. 5).
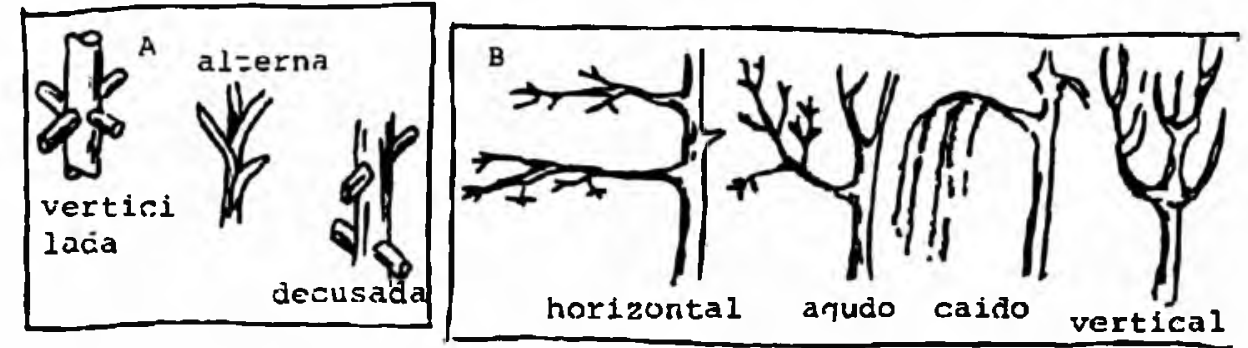

FIGURA 5 - Inserção dos galhos.

Fonte: A Ramalho (1976). B - Grey e Deneke (1978).

Desse modo, é a interação desses três elementos: ramificação, tipo de crescimento e disposição dos galhos que vai dar a forma final da árvore que será de interesse estético para a composição do conjunto. Assim temos tipos de formas específicas como: esférica, ovóide, umbeliforme, corimbiforme, tortuosa, cônica, cilíndrica, coluniforme, pendente (RAMALHO, 1976), globular, leque, informal, especial (MACEDO, 1990) (Fig. 6). Para o uso adequado de acordo com o que exige a estética é preciso conjugar a forma com o porte, para contornar problemas como fiação, calçadas, encanamentos, espaços, etc.

Cabe aqui, agora, para apresentação da idéia final, falar sobre espécies vegetais muito importantes no paisagismo que não possuem uma arquitetura ereta como as árvores. São as chamadas trepadeiras que, possuindo flores e cores variadas, são importantes, mas precisam de apoios artificiais como pérgulas, jiraus, ou cercas para entrarem na composição estética da paisagem.

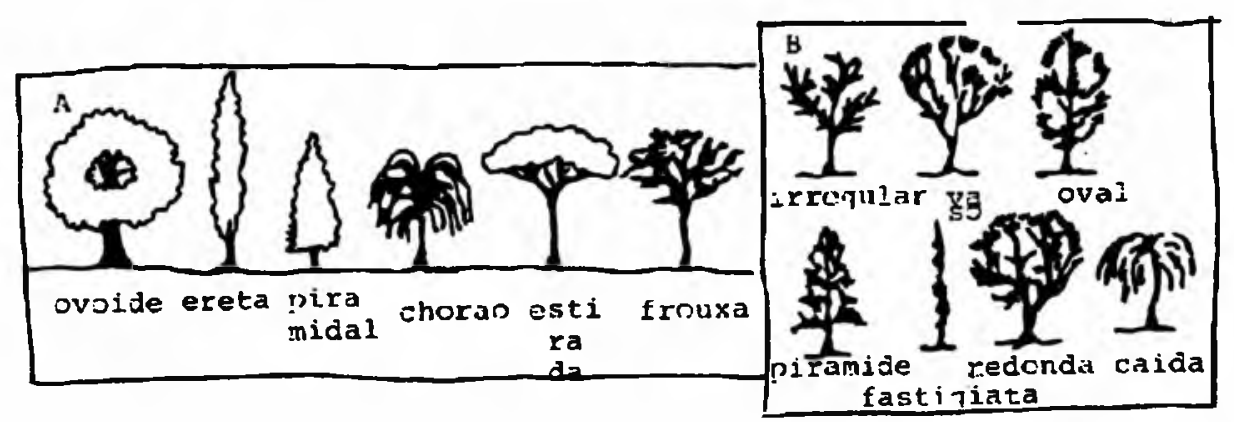

FIGURA 6 - Tipos de formas de árvores

Fonte: A - Fischesser (1980), B - Grey e Deneke (1978)

\section{EM BUSCA DE SOLUÇŌES}

Promover uma boa estética ao mesmo tempo em que se resolvem problemas físicos na arborização não é uma tarefa fácil. Supondo que em determinado espaço a arquitetura do Flamboyant (Delonix regia) seja a mais indicada esteticamente, o arborizador terá dois problemas a resolver: calçadas e paredes devido à super- 
ficialidade das raízes e fenologia, quando o aspecto da árvore em questão não é bom pela queda das folhas e aparecimento das vagens. Podemos supor também que a arquitetura de uma determinada árvore seja a mais indicada para o entorno, mas seu crescimento é exagerado para o local e o efeito só valeria para a árvore jovem (fiação, por exemplo): troca-se a árvore toda vez que ficar adulta ou poda-se constantemente.

O casamento de interesses entre a árvore que possui uma arquitetura ereta e a trepadeira que precisa de um apoio para se mostrar, pode ser um caminho para a busca da estética desejada. Na natureza é comum esse tipo de associação entre os seres proporcionando sensações visuais agradáveis.

As SOLUÇÕES para os problemas viriam com o uso da arquitetura da árvore morta, com uso de preservativos inclusive, servindo apenas como um apoio natural para a trepadeira. Assim, um flamboyant, por exemplo, emprestaria sua arquitetura sem necessidade de tantas raízes; uma árvore de crescimento exagerado seria sacrificada ainda quando jovem de forma que coubesse no espaço desejado apresentando sua arquitetura original. Essas associações podem contornar os problemas mais comuns na arborização como substituição de árvores, quebra de calçadas, DEPREDAÇÃO (a trepadeira pode ser plantada em um nível mais elevado, longe do alcance dos depredadores), fenologia (trepadeiras são de crescimento mais rápido, de troca rápida e algumas com floração permanente), fiação e espaços livres.

O uso dessas associações é praticamente ilimitado, estando na dependência única da criatividade do paisagista já que ele contará com diversos tipos de arquitetura e diversos tipos de trepadeira. Cada espaço a ser trabalhado exigirá do profissional uma solução própria (Fig. 7).
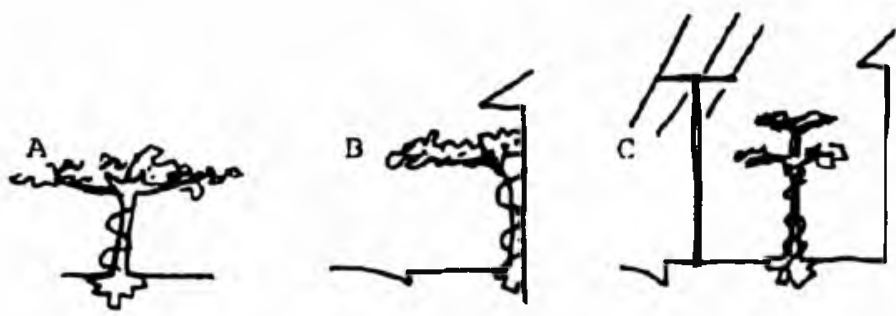

FIGURA 7 - Associaçōes para solução de problemas
A - uso de flamboyant sem raízes
B - uso de meio flamboyant em calçadas estreitas
C - uso da arquitetura de uma teminália sem raízes e com apenas dois estágios 


\section{CONCLUSÕES}

O modelo sugerido não foi testado, mas não é difícil imaginar associações como flamboyant e bougainvilea, terminália e alamanda, cupressus e brinco-de-princesa. Independentes disso, opiniões sobre ele podem ser previstas e discutidas:

a Embora possa parecer muito artificial, o modelo não o é mais que as pérgulas, os jiraus e as cercas.

b Ainda quanto a artificialidade o que se busca é o controle de artificialidades maiores como as podas usadas para contornar problemas da arborização.

c - Quanto ao sacrifício das árvores, o modelo não inova na medida em que elas já são abatidas para usos diversos. Apenas aqui valoriza-se a sua estética.

d - É prevista a necessidade de uma tecnologia adequada quanto à aplicação de preservativos e quanto a problemas de segurança como por exemplo a eliminação de galhos muito finos que possam causar acidentes.

e O modelo não preconiza a substituição das árvores vivas. Ao contrário, isso deve ser incentivado e só substituído em casos de extrema necessidade.

\section{BIBLIOGRAFIA}

FISCHESSER, B. Conhecer as ánores. Meyland: Euroagro, 1980, 275 p.

GREY, G. W., DENEKE, F. J. Urban Foresty. New York: John Wiley and Sons, 1978. 279 p.

HALLE, F.; OLDEMAN, R. A. A.; TOMLINSON, P. B. Tropical trees and forests an architectural analysis. Berlim: Springer, 1978. 441 p.

IEF Instituto Estadual de Florestas. Manual de Arborizaçāo. Belo Horizonte: CEMIG, s.d. 22 p.

LAURIE, M. Introducción a la arquitectura del paisage. Barcelona: Gustavo Gili, 1975. $304 \mathrm{p}$.

MACEDO, S. S. Plano de Massas - Um Instrumento para o Desenho da Paisagem. In: Paisagem e Ambiente - Ensaios III. São Paulo: FAUUSP, 1990. p. 25-41.

MAGALHÃES, I. M. de et al. Coexistência dos sistemas elétricos de distribuição e arborização. In: ENCONTRO NACIONAL SOBRE A ARBORIZAÇÃO URBANA, 3, Curitiba, 1990. Anais. Curitiba: FUPEF, 1990. p. 228-235.

RAMALHO, R. S. Dendrologia (Terminologia). Viçosa: UFV, 1976. 123 p. 
SARTORI NETO, J. P. Modelo de planejamento para a convivência da arborização com o sistema elétrico. In: CONGRESSO FLORESTAL ESTADUAL, 6, 1988, Nova Prata - RS, Anais. Nova Prata- RS, 1988. p. 219-256.

SEITZ, R. A. Considerações sobre a poda de árvores na arborização urbana. In: ENCONTRO NACIONAL SOBRE ARBORIZAÇÃO URBANA, 3, 1990, Curitiba, Anais. Curitiba, FUPEF, 1990. p. 87-100. 